Thorax (1964), 19, 571.

\title{
The diagnosis of emphysema
}

\author{
W. M. THUR L B E C K \\ From the Department of Pathology, Pathological Institute, McGill University, Montreal, Canada
}

Pulmonary emphysema is generally defined anatomically. It follows therefore that pathologists have the best opportunity to diagnose emphysema accurately. Whether they take advantage of this opportunity may be doubted by observers interested in lung disease, and Wyatt, Fischer, and Sweet (1961) have called the usual criteria (gross inspection and palpation of the lung and microscopic examination of random sections) 'pathologic chimeras'. There are, however, no investigations concerned specifically with the accuracy of the routine pathological diagnosis of emphysema, such as have been made for its clinical (Fletcher, 1952) and radiological diagnosis (Knott and Christie, 1951). This communication investigates the accuracy of the usual pathological methods in two ways.

\section{MATERIALS AND METHODS}

The prevalence of destructive pulmonary emphysema was determined in a random series of necropsies on patients more than 20 years of age who had died in the Royal Victoria Hospital, Montreal. The methodology was essentially the same as that described in an assessment of the prevalence of emphysema at the Massachusetts General Hospital, Boston (Thurlbeck, 1963). In brief, lungs were examined from necropsies performed in random weekly periods. At least one lung, which was distended with intrabronchial formalin to apparent full inflation, was obtained from each of the 150 necropsies performed in these periods. In 61 cases both lungs were available and the other lung in these cases was distended by a variety of techniques. The lungs were sliced and examined with a dissecting microscope using Heard's technique of barium impregnation (Heard, 1958). The emphysema was graded using a modification (Thurlbeck, 1963) of the grading proposed by a Ciba Guest Symposium in 1959. Where both lungs were available, the right lung was used for recognition and grading of the emphysema. These 150 cases will be referred to as the 'inflated lung group'.

The prevalence of emphysema, as diagnosed on random sections and uninflated lungs, was determined from the final diagnosis recorded in 1,000 consecutive necropsies performed on patients 20 years or over who died in the Royal Victoria Hospital before May 1, 1961.
The recorded prevalence of emphysema in the inflated and uninflated lung groups was compared.

In addition, 15 uninflated lungs were examined by six pathologists who were regularly involved in the supervision of necropsies. They were not aware of the age, sex or clinical histories of the 15 patients at the time of examination. Duplicate sections were cut from the blocks of the lung taken by the resident for histological examination and submitted to each pathologist. Their findings were recorded on a standard form. On the basis of their recorded opinions, the assessment of emphysema was placed in one of five categories:

(1) No emphysema: No emphysema recognized

(2) Minimal emphysema: Emphysema present but considered insufficient to cause symptoms

(3) Mild emphysema: Emphysema present, considered likely to cause mild symptoms

(4) Moderate emphysema: Emphysema present, considered likely to cause moderate symptoms

(5) Severe emphysema: Emphysema present, considered likely to cause severe symptoms.

The diagnosis of acute or compensatory emphysema by the panel of pathologists was excluded from the category of mild emphysema and regarded as acute hyperinflation. One observer recorded the finding of emphysema secondary to carcinomatosis. This was excluded as an example of emphysema.

The opposite lung in these cases was distended with formalin to apparent full inflation, and the amount of emphysema was assessed by the writer using the methods described for the 'inflated lung group' (above).

\section{RESULTS}

The age and sex of the cases in the inflated and uninflated lung groups are presented in Table $I$. It is apparent that the groups are comparable. The prevalence of emphysema in these groups is shown in Table II. The prevalence of emphysema was significantly greater $(P<0.05)$ in the inflated lung group $(41.3 \%)$ than that found in the uninflated group $(28.6 \%)$. This increase was due solely to the increased prevalence of lesions noticed in male lungs $(64 \%$ compared to $31.4 \%)$, since the prevalence of $17 \%$ in the inflated female lungs was lower than that recorded in the uninflated female lungs $(25 \%)$. The latter difference is not statisti- 
TAB LE I

AVERAGE AGE AND SEX Distribution OF THE TWO GROUPS

\begin{tabular}{l|c|c|c|c|c}
\hline & $\begin{array}{c}\text { No. of } \\
\text { Group }\end{array}$ & $\begin{array}{c}\text { Percen- } \\
\text { tage } \\
\text { of } \\
\text { Males }\end{array}$ & \multicolumn{3}{|c}{ Average Age (yr.) } \\
\cline { 5 - 6 } & Cases & Males & Females \\
\hline $\begin{array}{l}\text { Random inflated } \\
\text { lungs }\end{array}$ & 150 & 52 & $61 \cdot 1$ & $60 \cdot 8$ & $61 \cdot 4$ \\
Uninflated lungs $\ldots$ & 1,000 & $54 \cdot 9$ & $59 \cdot 5$ & 60.6 & $58 \cdot 2$ \\
\hline
\end{tabular}

TABLE I I

PREVALENCE OF EMPHYSEMA IN THE TWO GROUPS

\begin{tabular}{lc|c|c|c}
\hline & \multirow{2}{*}{$\begin{array}{c}\text { Prevalence } \\
\text { of } \\
\text { Emphysema } \\
(\%)\end{array}$} & $\begin{array}{c}\text { Prevalence of Emphysema } \\
(\%)\end{array}$ \\
\cline { 5 - 5 } & & Males & Females \\
\hline $\begin{array}{l}\text { Random inflated } \\
\text { 1,000 uninflated }\end{array}$ & $\cdots$ & $\begin{array}{c}41 \cdot 3 \\
28.6\end{array}$ & $\begin{array}{c}64 \cdot 0 \\
31 \cdot 4\end{array}$ & $\begin{array}{c}17 \cdot 0 \\
25 \cdot 0\end{array}$ \\
\hline
\end{tabular}

cally significant $(P>0.05)$, whereas the difference between the males is highly significant $(P<0.001)$. In both groups, the incidence of emphysema is higher in men than in women, but this difference is more marked in the inflated lung series.

Table III tabulates the assessment of emphysema in 15 uninflated lungs by the six different observers. Two lungs were seen by only five observers. The age and sex of the patients are tabulated in separate columns, as is the amount of emphysema in the contralateral inflated lung. This table shows that complete agreement was reached three times, once when emphysema was absent and twice when it was present. The opinions in these three cases agreed with the assessment of the emphysema made independently by the writer in the opposite (inflated) lung. In $\frac{\mathrm{O}}{-}$ the two cases where all observers agreed emphysema was present, they nevertheless differed in $\mathbb{\infty}$ their estimate of its severity.

\section{DISCUSSION}

It is hardly surprising that the prevalence of $\vec{\sigma}$ emphysema was found to be higher in a group of $\vec{F}$ carefully examined inflated lungs than in a retro- $x$ spective survey of iecorded diagnoses in a series $\overrightarrow{0}$ of necropsies in which only uninflated lungs were? available for routine observation. This might be $y$ attributed to greater enthusiasm in discovering $\vec{\circ}$ minor grades of emphysema in the inflated lungs, but this is not the reason as consideration of the $\dot{Z}_{Z}$ differing sex incidence readily gives evidence. The increased incidence of emphysema in the inflated $\Phi$ lungs is entirely due to the far higher incidence of $\frac{}{3}$ emphysema found in men. Another discrepancy between the uninflated and inflated lung groups $\vec{\bullet}$ is found when the incidence of emphysema is analysed by decade (Fig. 1). In the inflated lung group, the incidence rises rapidly from the fourth to the sixth decade and then flattens. On the other hand, the incidence as recorded in the uninflated lungs rises fairly steadily with age. It is apparent $\frac{\otimes}{\varnothing}$ therefore that the recorded diagnosis of emphy- $\varrho$ sema in the restrospective survey of uninflated $\overrightarrow{\overrightarrow{0}}$ lungs had a poor relationship to that recorded by 3 careful examination of inflated lungs. The latter group was carefully randomly selected to be representative of the necropsy population, and

TABLE III

SIX OBSERVERS' OPINIONS AS TO THE PRESENCE AND SEVERITY OF EMPHYSEMA IN 15 LUNGS

\begin{tabular}{|c|c|c|c|c|c|c|c|c|c|}
\hline \multirow{2}{*}{ Case } & \multicolumn{6}{|c|}{ Observer } & \multirow{2}{*}{ Other Lung } & \multirow{2}{*}{ Age } & \multirow{2}{*}{ Sex } \\
\hline & 1 & 2 & 3 & 4 & 5 & 6 & & & \\
\hline $\begin{array}{l}1 \\
2 \\
3 \\
4 \\
5 \\
6 \\
7 \\
8\end{array}$ & $\begin{array}{l}\text { None } \\
\text { Min. } \\
\text { Min. } \\
\text { Min. } \\
\text { None } \\
\text { None } \\
\text { Min. } \\
\text { None }\end{array}$ & $\begin{array}{l}\text { None }^{1} \\
\text { None } \\
\text { - } \\
\text { None } \\
\text { None } \\
\text { None } \\
\text { None } \\
\text { None }\end{array}$ & $\begin{array}{l}\text { Min. } \\
\text { Mod. sev. } \\
\text { None } \\
\text { Mild } \\
\text { None } \\
\text { None } \\
\text { None } \\
\text { None }\end{array}$ & $\begin{array}{l}\text { Min. } \\
\text { Mild } \\
\text { Mild } \\
\text { Mod. } \\
\text { Mild } \\
\text { None } \\
\text { Min. } \\
\text { None }\end{array}$ & $\begin{array}{l}\text { None } \\
\text { Mild } \\
\text { Mod. } \\
\text { Mod. } \\
\text { None } \\
\text { None } \\
\text { Min. } \\
\text { Mild }\end{array}$ & $\begin{array}{l}\text { None } \\
\text { None } \\
\text { None } \\
\text { Min. } \\
\text { None } \\
\text { None } \\
\text { Min. } \\
\quad\end{array}$ & $\begin{array}{l}\text { No emphysema } \\
\text { No emphysema } \\
\text { No emphysema } \\
\text { No emphysema } \\
\text { No emphysema } \\
\text { No emphysema } \\
\text { No emphysema } \\
\text { Mild panlobular emphysema tip of }\end{array}$ & $\begin{array}{l}38 \\
56 \\
62 \\
78 \\
38 \\
20 \\
89 \\
57\end{array}$ & $\begin{array}{c}\mathbf{F} \\
\mathbf{F} \\
\mathbf{F} \\
\mathbf{F} \\
\mathbf{M} \\
\mathbf{M} \\
\mathbf{F} \\
\mathbf{M}\end{array}$ \\
\hline 9 & Min. & Min. & Mod. & Mild & Min. & Min. & Minimal centrilobular emphysema & 52 & $\mathbf{M}$ \\
\hline 10 & None & None & None & None & None & Min. & Minimal centrilobular emphysema of & 44 & $\mathbf{F}$ \\
\hline 11 & Min. & Mod. & Min. & Mild & Min. & None & $\begin{array}{l}\text { Moderate centrilobular emphysema of } \\
\text { upper lobe }\end{array}$ & 58 & $\mathbf{M}$ \\
\hline 12 & None & None & None & None & Min. & None & $\begin{array}{l}\text { Mixed mild centrilobular and } \\
\text { panlobular emphysema }\end{array}$ & 56 & $\mathbf{M}$ \\
\hline 13 & Min. & Mild & Mild & Mild & Mild & Min. & Mixed mild centrilobular and & 57 & $\mathbf{M}$ \\
\hline 14 & Min. & Min. & Mild & Min. & None $^{2}$ & Min. & Mild centrilobular emphysema & 39 & $\mathbf{M}$ \\
\hline 15 & Min. & Mild & None & Mild & Mod. & Mild & $\begin{array}{l}\text { Moderate mixed centrilobular and } \\
\text { panlobular emphysema }\end{array}$ & 65 & $\mathbf{M}$ \\
\hline
\end{tabular}




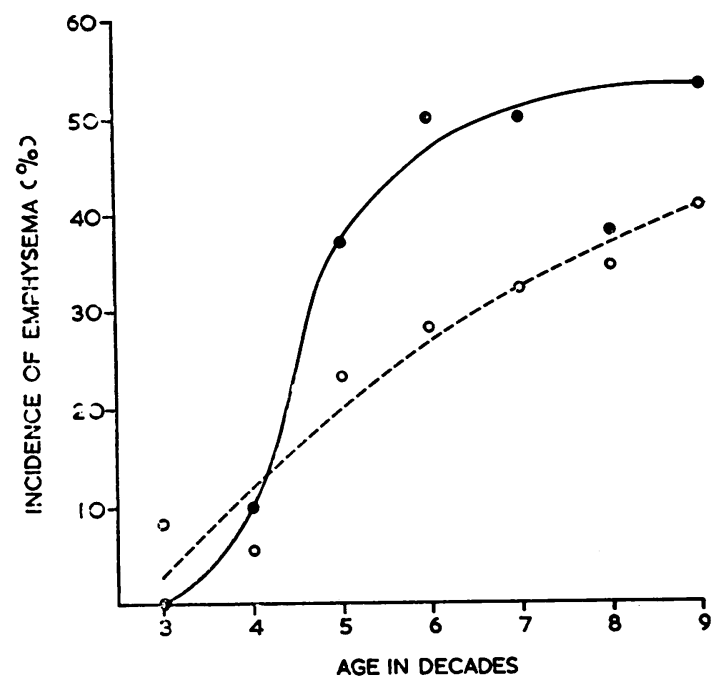

FIG. 1. The incidence of emphysema recorded in random inflated lungs (solid line) and in uninflated lungs (broken line, open circles) are compared by decade.

there is no reason to suspect that the prevalence of emphysema was in any way different in the two groups. It should also be noted that the age and sex incidence of emphysema of the random cases here was similar to that found in a necropsy population in Boston, U.S.A. (Thurlbeck, 1963) ; both studies were made on inflated lungs. The unmistakable conclusion that must be reached is that the diagnosis of emphysema in uninflated lungs is not dependable and that retrospective surveys of necropsies performed in the customary way will not provide evidence of any value concerning the prevalence of emphysema.

The diagnosis of emphysema on uninflated lungs is not completely inaccurate, however. Were this true, there should be no difference in the incidence in the two sexes. A significant difference $(\mathrm{P}<0.05)$ was, however, observed. One explanation for this difference is that pathologists were influenced by the clinical data. Emphysema, being more commonly diagnosed clinically in men, would therefore be more commonly recorded for men by the pathologists. It is for this reason that the second investigation was done. This showed that a unanimous decision as to the presence or absence of emphysema was reached in three of 15 uninflated lungs examined by six different pathologists. In no instance was there unanimity of opinion concerning the severity of the emphysema. If one assumes that emphysema is symmetrical-and an examination of the 61 pairs of lungs in the random series suggested that this is usually the case-and that the diagnosis made on the contralateral inflated lung was correct, then slightly more information can be obtained. Seven uninflated lungs, the opposite one of which showed no emphysema, were examined altogether 41 times and were considered emphysematous 19 times and non-emphysematous 22 times. In the 47 examinations made on eight uninflated lungs, the inflated contralateral lung of which was found to contain emphysema, emphysema was considered to be present 30 times and absent 17 times. A statistical analysis of these results is very difficult since the probability of the various observers making a correct diagnosis by chance cannot be computed with certainty. What is clear, however, is that there is considerable interobserver variation in the assessment of emphysema using uninflated lungs. Furthermore, their assessment correlated poorly with that made on the opposite inflated lung. On the assumption of bilateral symmetry and correct diagnosis in the contralateral lung, it appears that emphysematous lungs are not infrequently recognized as such, but that non-emphysematous lungs are often ragarded as emphysematous. The significant difference observed in the prevalence of emphysema in uninflated male and female lungs probably represents an imperfect recognition of the actual striking difference between the sexes, which is further confused by the frequent incorrect recognition of non-emphysematous lungs in both sexes.

Of further interest were two patients (14 and 15) who were included because they had clinically symptomatic chronic lung disease, from which one died. Neither lung was considered by all observers to show emphysema, and only one was thought, by a single observer, to show more than mild emphysema.

The assessment of emphysema by routine examination of the lung is therefore not entirely erroneous, it is merely poor. The usual routine methods for examining lungs seem unlikely to provide adequate data for clinico-pathologic studies.

\section{SUMMARY}

The prevalence of emphysema in inflated, fixed lungs observed in an adequately examined random sample of necropsies was compared with that recorded in a similar population whose lungs were not inflated post mortem. The adequately examined cases (inflated lung group) showed a greater prevalence of emphysema due entirely to the 
increased incidence found in men. The sex and age distributions of emphysema in the uninflated lung group showed little similarity to those of the inflated lung group, but there was a significant difference in prevalence recorded between the sexes in both groups.

Fifteen uninflated lungs were examined by six pathologists who recorded the absence or presence of emphysema and its severity. A unanimous opinion was expressed concerning the absence or presence of emphysema in three of the 15 lungs. In no instance was there unanimity concerning the severity of the emphysema present. A moderately severe, and clinically symptomatic, degree of emphysema may easily be disregarded, and these lungs may even be regarded as nonemphysematous.

It is concluded that the routine diagnosis of emphysema on uninflated lungs is poor rather than erroneous, and that it probably serves no useful function.

I am indebted to the pathologists at the Pathological Institute and at the Montreal General Hospital for their co-operation in examining the lungs referred to here.

This work was supported by the American Thoracic Society and the Medical Research Council of Canada.

\section{REFERENCES}

Ciba Guest Symposium (1959). Terminology, definitions, and classification of chronic pulmonary emphysema and related conditions. Thorax, 14, 286.

Fletcher, C. M. (1952). The clinical diagnosis of pulmonary emphysema-an experimental study. Proc. roy. Soc. Med., 45, 577

Heard, B. E. (1958). A pathological study of emphysema of the lungs with chronic bronchitis, Thorax, 13,136.

Knott, J. M. S., and Christie, R. V. (1951). Radiological diagnosis of emphysema. Lancet, 1, 881 .

Thurlbeck, W. M. (1963). The incidence of pulmonary emphysema. Amer, Rev, resp. Dis., 87, 206.

Wyatt, J. P., Fischer, V. W., and Sweet, H. (1961). Centrilobular emphysema. Lab. Invest., 10, 159. 